УДК 581.96 (95)

DOI $10.21661 / \mathrm{r}-467642$

А.Ш. Ибрагимов, Ф.Х. Набиева

НОВЫЙ ВИД БЕРЕЗЫ И НОВОЕ МЕСТОНАХОЖДЕНИЕ BETULA PENDULA НА ТЕРРИТОРИИ НАХЧЫВАНСКОЙ АВТОНОМНОЙ РЕСПУБЛИКИ

Аннотация: впервые авторами выявлен новой для флоры Нахчыванской АР Betula raddeana Trautv. (в культуре) из рода Betula L. (Betulaceae Dumort.). Обнаружен 02.12.2017 г. в городе Нахчыван. Выявлены также новые местонахождения Betula pendula Roth. в Ордубадского района окр. сел. Парагачай, Агдара, между сел. Мазра - Урмыс, в окр. сел. Билав, Парага и между Билав - Тиви 16002600 м над ур. м. в Ордубадском районе. Изучено их народнохозяйственное и медицинское значение.

Ключевые слова: семейства, род, вид, новый, береза, местонахождения.

\author{
A.Sh. Ibragimov, F.Kh. Nabieva
}

\title{
NEW SPECIES OF BIRCH AND A NEW LOCATION OF BETULA PENDULA ON THE TERRITORY OF THE NAKHCHYVAN
} AUTONOMOUS REPUBLIC

Abstract: for the first time the authors have revealed a cultural species Betula raddeana Trautv. of the genus Betula L. (Betulaceae Dumort.), for the flora of the Nakhchivan AR collected 02.12.2018 in the city of Nakhchivan. New locations of Betula pendula Roth. were also revealed Ordubad district - Paragachay, Agdara, between the villages of Mazra and Urmys, in the vicinity of the settlements of Bilav, Paraga and Bilav-Tivi 1600-2600 m above sea level. The birch species are of national economic and medical importance.

Keywords: family, genus, species, new, birch, locations.

В настоящее время одним из современных важнейших геоботанических исследований признается комплексное изучение экобиоморф как основа познания 
структуры растительных сообществ. Выявление состава экобиоморф в растительном покрове и выяснение их роли в сложении фитоценозов позволяют изучить историю и закономерности формирования, строение и динамику растительных сообществ, и их отношение к окружающей среде. Экобиоморфы - это адаптационные системы, сформировавшиеся и существующие в определенной обстановке. Экобиоморфы, свойственные той или иной территории, могут служить индикаторами ее природных условий. Высокий континентальность климата, суровые зимы, сухое и знойное лето, сильно пересеченный рельеф, преобладание примитивных, сильно скелетных почво-грунтов, а также скал и осыпей на склонах, подверженных эрозионным процессам, оказали сильное влияние на формирование современной растительности. Преобладающими типами растительности здесь являются пустынная, полупустынная, нагорно-ксерофитная и горно-степная; в меньшей степени развиты луга и совсем слабо - леса [8; 10, с. 90-95].

Всестороннее исследования и оценка современного состояния лесных экосистем является одним из основных вопросов для их рационального использования, восстановления и охраны. В далеком прошлом исследуемый регион был заняты лесами (более 30 тыс. га), однако в результате систематической вырубки резко сократился их ареал $[3$, с. 46; 4, с. $19-23 ; 5,117-123 ;$ 6, с. 32-33; 7, с. 63-71]. В настоящее время в Нах. АР лесов очень мало, в локальной форме можно встретить всего лишь несколько лесных массивов, которые находясь во взаимосвязи с ксерофитной растительностью гор и субальпийской растительностью, образуют специфические формации лесных сообществ, характерные для этого региона. Основной причиной этого является резко континентальный климат и особенности орографических условий. Под лесами данного района исследования залегают горнолесные почвы. Общее количество выпадающих осадков равно 660 мм. В засушливые годы этот показатель снижается до 370-400 мм. Лесные угодия в зависимости от вертикальной и горизонтальной зональности размещены по разному: на высоте 1800-2400 (2600) м равномерно, отдельными пятнами встречаются в ущельях, а на склонах гор с крутизной $10-40^{\circ}$ носят интразональный характер. 2500 га лесных площадей расположены в Шахбузском, 
400 га в Джульфинском, 840 га в Ордубадском районах. В Джульфинском районе лесные массивы приурочены к Биченаку, Батабату, в Шахбузском районе лесные угодья расположены вблизи сел. Арафса, Лакатаг (Хазинадара, Тингелик, Караторпаклык, Венли-дара, Гявик, Гянджи, Кола и Думан). Здесь отмечены также леса Сафаралы, Алджафар, Калба-Орудж. В Ордубадском районе леса Тиллек, Палыдлыдере, Юхары Джалил, Ашагы Джалил, Талалар и Азнамер. Помимо островных дубовых лесов, на территории края отмечены березняки и можжевельниковое редколесье. Впервые Л.И. Прилипко [8] для Нах. АР была предложена следующая классификация лесной растительности: дубовые леса, ясенево - дубовые, боярышниковое - дубовые, светлые леса каменистых южных склонов, арчевые леса горных ущелий, речных долин и вторичные кустарниковые леса. Однако следует что в этой классификации не отражено с исчерпывающей полнотой богатство этих лесов. С этой целью нами было проведено детальное геоботаническое изучение леса и кустарники, связанные с высокогорными лугами [1, с. $168-170 ; 5]$. На основе проведенных крупномасштабных исследований нами составлена многоступенчатая классификация, включающая 4 классов формаций, 23 формаций и 23 ассоциаций. Основным строителем горных лесов Нах. АР является дуб восточный Quercus macranthera Ficsh. et C.A. Mey. ex Hohen иногда к нему примешивается иберийский дуб Quercus iberica Stev. и Quercus boisseri Reut. Подробно описаны горные лесные формации края, занимающие всего лишь 3376 га. Они малопродуктивны, низкорослы и малопригодны в хозяйственном отношении, но в ландшафтном плане играют важную роль. Главенствующее значение принадлежит дубовым и боярышниковым лесам, представленным разными вариантами. Эдификаторы, которое в условиях высокогорий имеют широкую экологическую амплитуду, проявляют большую пластичность, образуют экоморфы и формируют множество сообществ. Дубовые леса носят парковый характер, изобилуют сухостоем и суховершинными отложениями. Высокогорные дубовые леса - Querceta, по сравнению с другими лесными формациями распространены довольно широко. Дубовый лес, формируясь на юго-восточных, северо-восточных и северо-западных склонах гор, поднимается до 
высоты 1800-2400 (2600) м. Изолированные друг от друга крутыми каменистощебенистыми склонами, безлесными площадями они приобрели форму парковых насаждений. В такой форме дубовый лес развивается как в чистом, так и в смешанном виде. Чисто дубовые леса встречаются в массивах Биченака, Батабата, Юхары Джалилли, Палыдлыдере и Гявика.

Березовые леса в пределах Нах. АР впервые нами обнаружено криволесье из Betula pendula Roth [2, с. 46]. Представитель третичного периода - долголетия B. pendula достигает высоты 7-8 м, диаметр кроны равен 4-5 м, толщина ствола 25-30 см. Криво ствольная береза образует рощи в субальпийском поясе преимущественно на высоте 2400 м (2600 м). В частности, достаточно широко, она представлена на верхней границе леса Тиллек Ордубадского района под названием леса Ашагы Джалил и Юхары Джалил. В березняке встречаются также Quercus macranthera Ficsh., Q.iberica Stev., Fraxinus exelsior L., Viburnum montana L., Sorbus graeca Schauer, Acer ibericum Bieb., Pyrus salicifolia Pall., P. syriaca Boiss., Malus oriantalis Uglitzk., Prunus divaricata Ledeb., а из травянистых растений-Heracleum trachyloma Fisch., H. pastinacifolium C.Koch, Briza minor L., Chamaemelum monticolum Boiss. et Huet., Trifolium canescens Willd, Polygala anatolica Heldr., Malva oriantalis Uglitzk., Inula helenium L. и др. Выявлены новые местонахождения Betula pendula в долине Гильянчая, вблизи сс. Билав, Парага, Бухруд Ордубадского района (рис. 1).

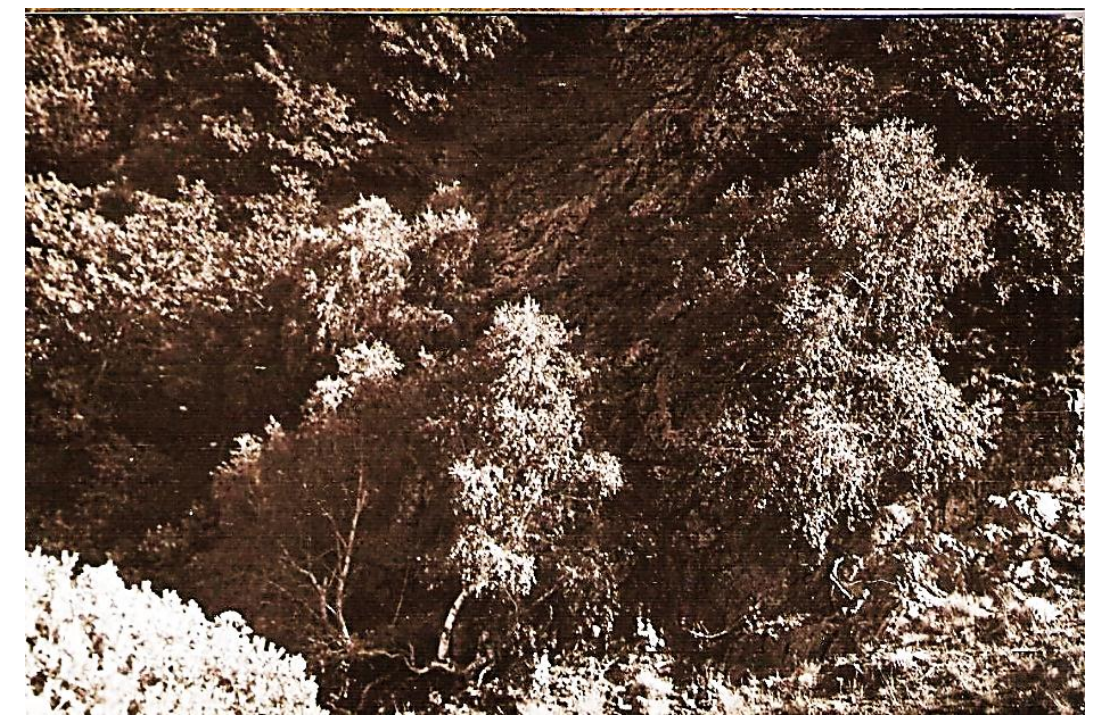

Рис. 1. Криволесье из Betula pendula Roth. 
Здесь она встречаются мелкими группами и образует смешанные фитоценозы с Salix alba L., S. wilhelmsiana Bieb., Populus euphratica Oliver, P. gracilis Grossh., Ulmus glabra Huds., U. scabra Mill., а также кустарниками как Rosa canina L., Crataegus orientalis Pall. ex Bieb., C. meyeri Pojark. а в 2003г. обноружена на г. Союг (2400-2600 м), которое образует чистые березовые леса Betuleta. Coздает новое сообщества с другими древесно-кустарниковыми породами как Sorbus graeca Schauer, Acer ibericum Bieb. и др. Большая часть травостоя состоит из представителей субальпийской растительности. Формация Betuleta в исследуемом регионе представлена 6 ассоциациями: дубово-березовая (Betula pendula + Quercus macranthera); дубово-ясенево-березовая (Betula pendula + Fraxinus excelsior + Quercus macranthera); березово-облепиховая (Betula pendula + Hyppophae rhamnoides); березово-кленовая (Betula pendula + Acer iberica); яceнево-березовая (Fraxinus exelsior + Betula pendula); ивово-высокотравно-березовая (Betula pendula + Salix caprea + Altherbosa). На относительно периферийных участках леса береза смешивается с двумя видами (Salix caprea L., S. phlomoides) и образует ивовый березняк (Betuleto-Salicetum), где отмечены Cotoneaster multiflorus Bunge и Sorbus persica Hedl.

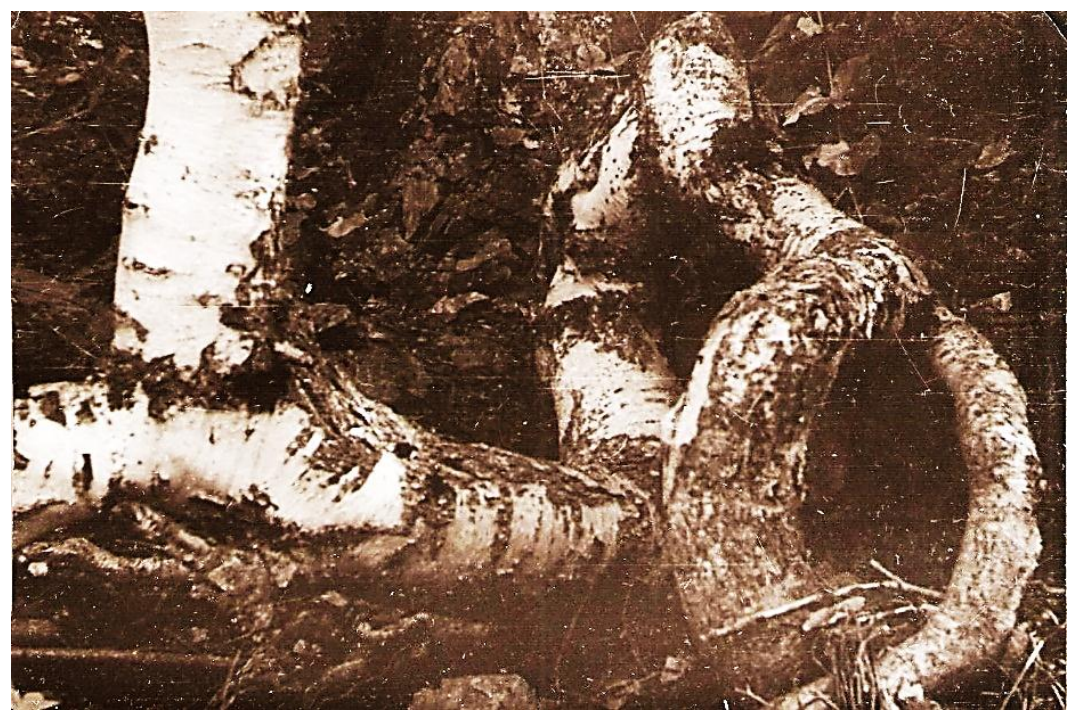

Рис. 2. Кривая ствола Betula pendula Roth.

Новая местонахождения березовая леса 24.06.2014г. на высоте 2750-2800 м обнаружено Т.Г. Талыбовым и А.Ш. Ибрагимовым гора Союг Ордубадского района. Высокотравный березняк развит на относительно менее влажных 
северных склонах. Травостой здесь очень высок и некоторые виды достигают 1,5-2,0 м. Основные представители его Senecio othonnae Bieb., Aconitum nasutum Reichenb., Doronicum macrophyllum Fisch., Heracleum trachyloma Fisch., Antriscus sylvestris Hoffm., Conium maculatum L. Видовой состав дубово-ясенево-березовых ассоциаций очень богат и разнообразен. Нами для этой ассоциаций выделено более 60-65 видов, из них около 30-40 являются постоянными спутниками: Primula macrocalyx Bunge, Rindera lanata, Campanula trautvetteri Grossh., Papaver orientale, Ornithogalum ponticum Zahar., Aconogonon alpinum (All.) Schur, Agrimonia eupatoria L., Fillipendula vulgaris Moench., Thalictrum minus, Berberis vulgaris L., Origanum vulgare L., Rosa sosnowsyana, Juniperus sabina L., Piptatherum virescens (Trin.) Boiss., Alopecurus aequalis Sobol., Asyneuma campanuloides Bornm., Seseli peucedanoides, Pastinaca armena Fisch., Sedum gracile C.A.Mey., Libanotis transcaicasica Schischk., Trifolium pratense.

Поиск других местонахождений, дикорастущие или культурные виды березы нами всегда интересовал. Наконец, 2018 г. в городе Нахчыван обнаружили для флоры автономной республики второй вид Betula raddeana Trautv. (в культуре) в состоянии плодоношение. Местонахождения вида является, аллея мечет Турции. Здесь отмечено 3 древесные экземпляры с высотой 3,5 м где, интродуцированы с целью обогащение озеленении (рис. 3).

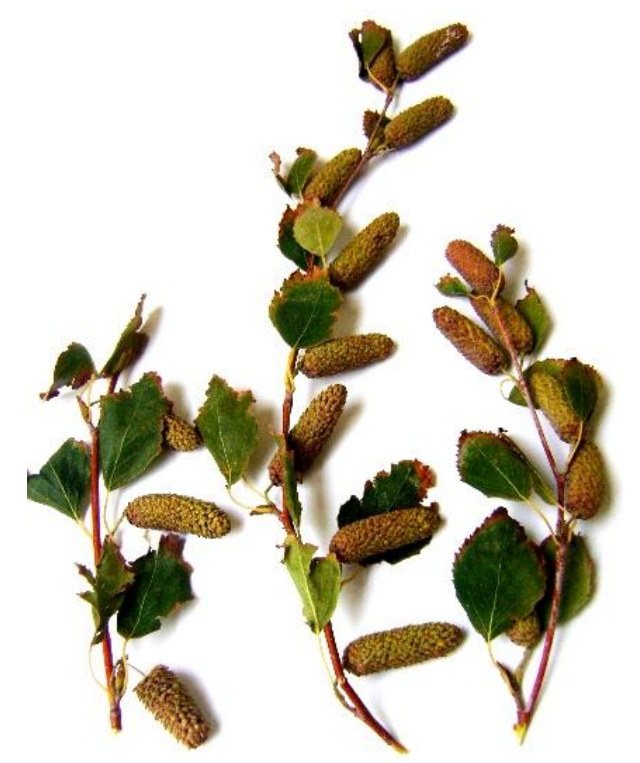

Pис. 3. Betula raddeana Trautv. 
05-06.12.2018 г. во время экспедиции по изучению плодово-ягодные ресурсы региона выявлено 2 новые местонахождения Ордубадском районе. 1. Северо-западном части селений Пазмари - Урмыс на высоте 1600-1800 м над ур. моря. Месторасположения крутые, каменисто-скальные склоны, овраги, ущелье и древесно-кустарниковой заросли с травянистым покровом. Здесь высота береза достигает 7-8 м. Проективный покров составляет 95-98\%. Она на древесно-кустарниковых зарослях с участием Salix phlomoidts, S. caprea, Prunus divaricata, Pirus salicifolia, Rosa canina, R. corumbifera, Acer campestre является доминантам и занимает первый ярус. А в лесах с Quercus macranthera, Q. iberica, Frachynus exelsior, Juniperus foetidissima и др. занимает вторй ярус.

Вторая местонахождения вида обнаружено вдоль в берега р. Парагачай, рудник Парагачай и Агдара. Это местонахождения труднодоступное, довольно огромные и занимает обширные территории. Месторасположения крутые, каменисто-скальные склоны, овраги, ущелье и россыпи. Здесь преобладает деревья, кустарники и травянистые растения. Отмечено около 115-120 видов растений. Часто встречаются 65-70 видов. Проективное покрытие составляет 98-100\%. Видовой состав данного фитоценоза богат и разнообразен. Преобладает плодовые породы деревьев и кустарники. Такие как, Malus orientalis Uglitzk., Pyrus zangezura Maleev, P. salicifolia Pall., Prunus divaricata Ledeb., Cotentaster integerrimus Medik.,, C. melanocarpus Fisch., Rhus coriaria, Crataegus orientalis Pall. ex Bieb., C. meyeri Pojark., Rosa canina L., R. rahinii Boiss. et Bal. из других пород - Acer ibericum Bieb., A. campestre L., Salix alba L., S. caprea L., Swida australis Pojark., Rhamnus cathartica L., Lonicera iberisa Bieb. и др. Травянистый покров богат кормовым, лекарственным, эфирно масличным (Grammosciadium platycarpum (Boiss. et Hausskn.) Schischk., Ziziphora biebersteiniana Grossh., Prongos ferulacea (L.) Lindl.) и другим полезным растением. Из редких растение выключенных в Красную книгу растений имеются Nectaroscordum tripedale Grossh.

Таким образом, в результате долголетних (1970-2017) исследование флоры и растительности края выявлено 2 вида березы: Betula pendula Roth., B. raddeana 
Trautv. и около 10 новые местонахождение для Betula pendula Roth. Она выключено нами в «Красную Книгу» Нахчыванской Автономной Республики [9, с. 298-300], а все обнаруженные местонахождение взято под контроль Ордубадском Национальном Парке для охраны. Целесообразно заниматься их интродукции введению в культуре и использовать озеленении.

\section{Список литературы}

1. Ибрагимов А.Ш. Новые данные о флоре высокогорий Нахичеванской АССР // Тезисы докл. Всесоюз. совещ. по изучению и освоению флоры и растительности высокогорий. - Ставрополь, 1974. - С. 168-170.

2. Ибрагимов А.Ш. Березовые леса в Нахчыване // Природа Азербайджана. - 9-е изд. - Баку, 1977. - С. 31.

3. Ибрагимов А.Ш. Охрана генофонда флоры и растительности высокогорий Нахичеванской АССР // Мат. Всесоюз. Симп. «Охрана генофонда природной флоры». - Новосибирск, 1980. - С. 46.

4. Ибрагимов А.Ш. Лесная растительность Нахчыванской Автономной Республики Азербайджана / А.Ш. Ибрагимов, Ф.Х. Набиева // IV Международная научно-практическая конференция «Актуальные вопросы современных математических и естественных наук». - Екатеринбург, 2017. - С. 19-23.

5. Ибрагимов А.Ш. Некоторые сведение о растительности лесах и после лесных лугах Нахчыванской АР // Флора и растительность Нахичеванской АР. Ваку: Элм, 1981. - С. 117-123.

6. Ибрагимов А.Ш. Редкие виды растений во флоре Нахичеванской АССР / А.Ш. Ибрагимов, В.Д. Гаджиев // Материалы - научные советы АН СССР и АН Азербайджанской ССР по проблеме «Биологические основы рационального использования, преобразования и охраны растительного мира» (18-20 мая 1982 г.). - Кировабад - Баку, 1982. - С. 32-33.

7. Ибрагимов А.Ш. Фитоценологическая структура лесов Нахчыванской АССР // Комплексное использование природных ресурсов Нахчыванской АССР. - Баку: Элм, 1984. - С. 63-71. 
8. Прилипко Л.И. Растительные отношения в Нахичеванской АССР // Труды Ботанического Института. Т. VII. - Изд. Аз. ФАН., 1939. - 196 с.

9. Талыбов Т.Г. Красная книга Нахчыванской Автономной Республики / Т.Г. Талыбов, А.Ш. Ибрагимов. - Нахчыван: Аджами, 2010. - С. 298-300.

10. Флора Азербайджана. Т. 3. - Баку: Изд-во Академии Наук Азербайджанской ССР, 1952. - С. 90-95.

\section{References}

1. Ibragimov, A.Sh. (1974). Novye dannye o flore vysokogorii Nakhichevanskoi ASSR. Tezisy dokl. Vsesoiuz. soveshch. po izucheniiu i osvoeniiu flory i rastitel'nosti vysokogorii, pp. 168-170. Stavropol'.

2. Ibragimov, A.Sh. (1977). Berezovye lesa v Nakhchyvane. Priroda Azerbaidzhana, p. 31. Baku.

3. Ibragimov, A.Sh. (1980). Okhrana genofonda flory i rastitel'nosti vysokogorii Nakhichevanskoi ASSR. Mat. Vsesoiuz. Simp. "Okhrana genofonda prirodnoi flory", p. 46. Novosibirsk.

4. Ibragimov, A.Sh., \& Nabieva, F.Kh. (2017). Lesnaia rastitel'nost' Nakhchyvanskoi Avtonomnoi Respubliki Azerbaidzhana. IV Mezhdunarodnaia nauchnoprakticheskaia konferentsiia "Aktual'nye voprosy sovremennykh matematicheskikh i estestvennykh nauk", pp. 19-23. Ekaterinburg.

5. Ibragimov, A. Sh. (1981). Nekotorye svedenie o rastitel'nosti lesakh i posle lesnykh lugakh Nakhchyvanskoi AR. Flora i rastitel'nost' Nakhichevanskoi AR, pp. 117123. Vaku: Elm.

6. Ibragimov, A.Sh., \& Gadzhiev, V.D. (1982). Redkie vidy rastenii vo flore Nakhichevanskoi ASSR. Materialy - nauchnye sovety AN SSSR i AN Azerbaidzhanskoi SSR po probleme "Biologicheskie osnovy ratsional'nogo ispol'zovaniia, preobrazovaniia i okhrany rastitel'nogo mira", pp. 32-33. Kirovabad; Baku.

7. Ibragimov, A.Sh. (1984). Fitotsenologicheskaia struktura lesov Nakhchyvanskoi ASSR. Kompleksnoe ispol'zovanie prirodnykh resursov Nakhchyvanskoi ASSR, pp. 63-71. Baku: Elm. 
8. Prilipko, L.I. (1939). Rastitel'nye otnosheniia v Nakhichevanskoi ASSR. Trudy Botanicheskogo Instituta, p. 196. Az. FAN.

9. Talybov, T.G., \& Ibragimov, A.Sh. (2010). Krasnaia kniga Nakhchyvanskoi Avtonomnoi Respubliki. Nakhchyvan: Adzhami.

10. (1952). Flora Azerbaidzhana. Baku: Izd-vo Akademii Nauk Azerbaidzhanskoi SSR.

Ибрагимов Алияр Шахмардан оглы - д-р биол. наук, профессор, руководитель отдела «Систематика растений» Института биоресурсов Нахчыванского отделения НАН Азербайджана, Азербайджанская Республика, Нахичевань.

Ibragimov Aliiar Shakhmardan ogly - doctor of biological sciences, professor, head of the «Systematics of plants» Department at the Institute of Bioresources Nakhchivan branch of the National Academy of Sciences of Azerbaijan, the Republic of Azerbaijan, Nakhichevan.

Набиева Фатмаханум Халид кызы - канд. с.-х. наук, доцент, ведущий научный сотрудник Института биоресурсов Нахчыванского отделения НАН Азербайджана, Азербайджанская Республика, Нахичевань.

Nabieva Fatmakhanum Khalid kyzy - candidate of agricultural sciences, docent, leading researcher at the Institute of Bioresources of Nakhchivan branch of the National Academy of Sciences of Azerbaijan, the Republic of Azerbaijan, Nakhichevan. 